\title{
Language as lever: Can the lexicon of local make a global impact?
}

Book review by Stacy Miller*

Independent consultant

\section{Local: The New Face of Food and Farming in America, by Douglas Gayeton}

Gayeton, D. (2014). Local: The new face of food and farming in America. New York: Harper Design. Available as hardcover and ebook. Publisher's website: http://www.harpercollins.com/books/9780062267634

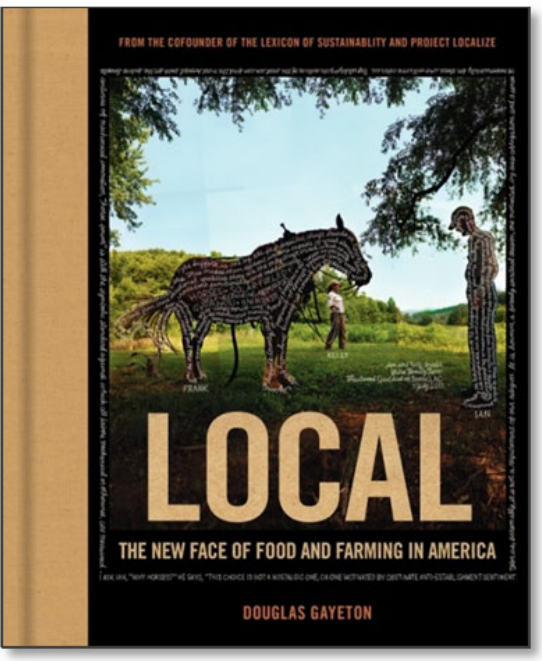

Published online August 19, 2014

Citation: Miller, S. (2014). Language as lever: Can the lexicon of local make a global impact? [Book review of Local: The new face of food and farming in America]. Journal of Agriculture, Food Systems, and Community Development, 4(4), 207-212. http://dx.doi.org/10.5304/jafscd.2014.044.008

Copyright (C) 2014 by New Leaf Associates, Inc.

"Lacking any intrinsic value, words are only valuable in an instrumental way. Thus, the value of words resides in their ability to accomplish something." -Michael Suarez, The Book: A Global History

$\mathrm{I}^{\mathrm{n}}$ nfused with the ambitious energy of spring, I eagerly volunteered to review Local: The New Face of Food and Farming in America by Douglas Gayeton. By June, I felt a bit like Alice, plunged into a multimedia wormhole wonderland. The book is only one fruiting body of The Lexicon of Sustainability Project, founded in 2009 by Douglas

\footnotetext{
* Stacy Miller is an independent writer, research advisor, and program consultant who helps organizations evaluate and improve food system diversity, transparency, and integrity. As the former executive director of the Farmers Market Coalition and researcher into local food issues, Stacy has coauthored several reports, including Real Food, Real Choice: Connecting SNAP Recipients with Farmers Markets (2010). Her current projects involve identifying metrics and practical data collec-
}

and his wife, Laura Howard-Gayeton. The website says the project "educates, engages, and inspires people to pay closer attention to how they eat, what they buy, and where their responsibility begins for creating a healthier, safer food system in America" ("Local': The Book," n.d., para. 4). You have likely encountered Gayeton's information artworks, seen one of 24 beautifully bite-sized short films as part of PBS's Know Your Food film series, or perhaps checked out the website, http://www.lexiconofsustainability.com. If you haven't, you will. In fact, go ahead. I'll wait.

Unique artistry aside, Local is a different kind of book, which is obvious from its first page. Here,

tion methodologies for farmers market evaluation and local food system integrity. Stacy has a master's in agricultural and environmental education from West Virginia University. She can be emailed at goodphyte@gmail.com, found on Twitter @goodphyte, or in her "biodiverse" garden in Charlottesville, Virginia, which is home to a startling variety of weeds and rodents with sophisticated vegetarian palates. 
the author implores the reader to give it away. He knows that his work does not belong on your shelf, or even on posters at a sustainable agriculture conference. The book belongs on your socialite Aunt Helen's coffee table, the information artworks plastered on the wall of a public library or a restaurant bathroom stall, and the videos played in high school homeroom. In short, if you are reading this book review, you are more than likely not its target audience.

This is why I begin my review with Local's last page rather than the first. It's here, in the afterword, that Gayeton fesses up: the purpose of every photograph, interview, and anecdote, he admits starkly, is to "explain climate change" (p. 270). He does this by distilling complex system issues into more accessible, palatable, and solutions-oriented vocabulary, using food as the lens. Refreshingly, he leaves the gory guilt trips to food documentaries of the Food, Inc., ilk; he instead offers a comprehensive, illustrated glossary of terms for myriad solutions happening on farms, fisheries, co-ops, bakeries, seed libraries, back yards, and city rooftops that, collectively, just might add up to systems change.

There are few forks unturned in this visually engaging book, as Gayeton attempts to elucidate elements of culture (e.g., food sovereignty), politics (e.g., veggie libel laws), and economics (e.g., true cost accounting) in relation to food being produced, distributed, sold, and consumed. Some The Lexicon of Sustainability. terms, like locavore, are familiar to nearly anyone, while others tend toward the academic ecologist (e.g., filter feeding bivalves, mycoremediation).

I give a lot of credit to a former film director who can find a compelling poster child for, and condense the complexities of, expansive terms like economies of community (see Figure 1), soil food web, $G M O$, or traceability. With my bias as former executive director of the Farmers Market Coalition, I initially bristled at the omission of farmers market as a term, but can appreciate how it actually serves to expand the reader's traditional trope for "local food." Farmers markets are, after all, the stage for his terms locavore and $S N A P$, both of which were photographed at markets.

A person and a place illustrate each of the more than 200 terms featured in the book, which

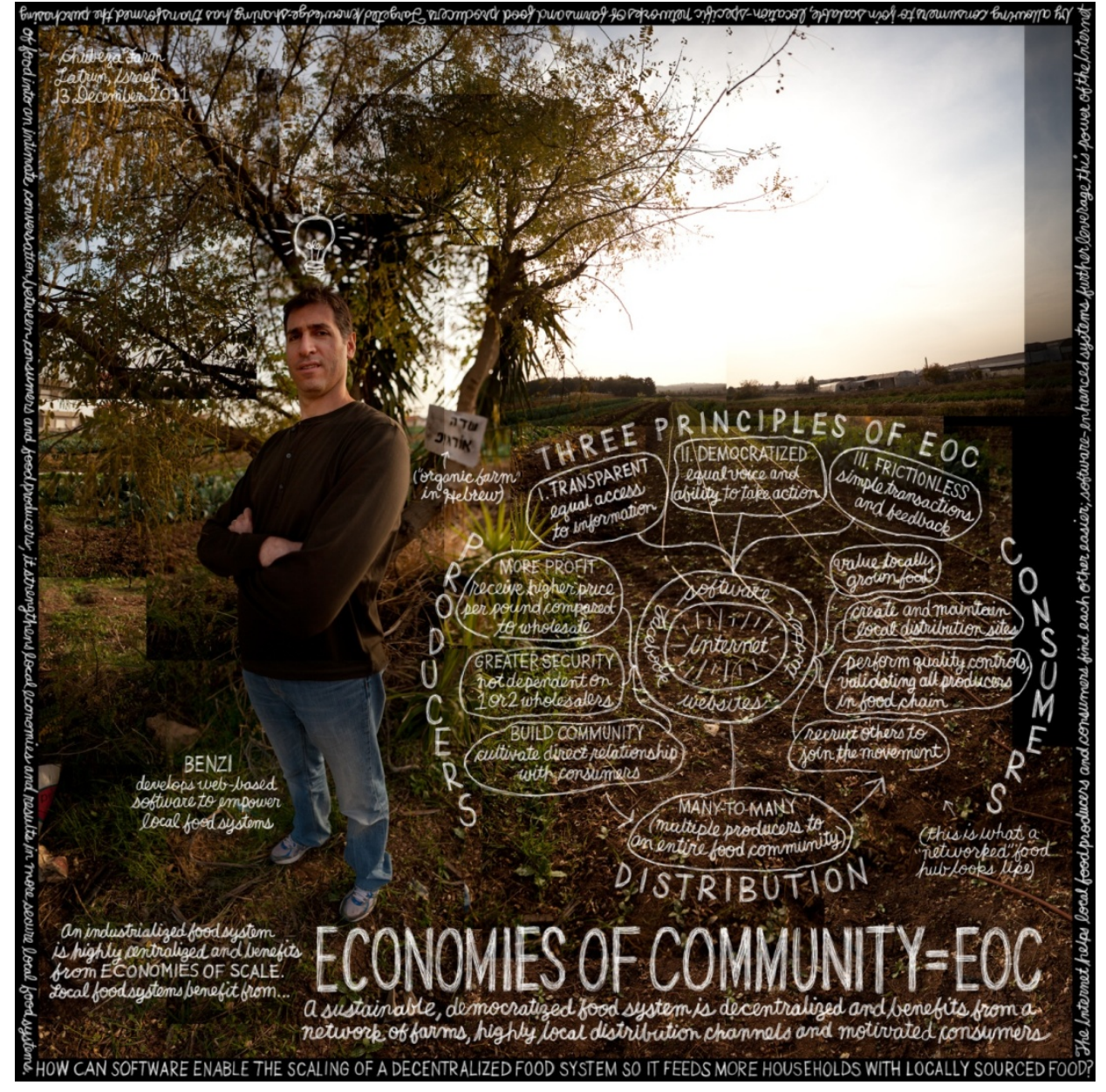

Figure 1. Economies of community is one of the more than 200 illustrated terms included in Local, featuring Benzi Ronen of Chubeza Farm in Israel (p. 28). Image used with permission of 
Gayeton says took his team four years to identify and vet with 500 thought leaders around the United States. There are the obvious (and still venerable) poster children - Alice Waters, Joel Salatin, Temple Grandin, Eliot Coleman, Wes Jackson, Will Allen, and others — whose published works or features in documentaries have given them some status in popular culture. And indeed, they are responsible for some of the many goldennugget quotations, like "Chemical fertilizers instill soil with an imposter vitality, a bit like plastic surgery" (John Peterson, featured in the documentary The Real Dirt on Farmer John). Some of the more valuable profiles, however, represent lesser known terms like forest raised, maximum sustainable yield (MSY), and crop rent calculator. Gayeton amply covers the fishery sector, problems with which the media have been slow to examine even as nutritionists stress the value of fish in the human diet.
Here, terms like tragedy of the commons, keystone species, chains of custody, and exclusive economic zones are explored.

The disciplined cursive annotating each artwork will be familiar to readers of Gayeton's 2009 book, Slow: Life in a Tuscan Town. In this case, the text in the border is not author commentary but is instead the actual words of the person or people featured in the image (for example, see Figure 2).

While some subject matter experts might be tempted to dismiss the "snapshot" nature of each term's profile as cursory, skeptical that anyone could explain external costs in a single-page image, most of the artwork does much more than simply scratch the surface. In a handful of cases, this is problematic, as the relationships between terms featured on different pages seem disjointed. I found myself squinting with the book inches from my face in order to read the nearly inscrutable

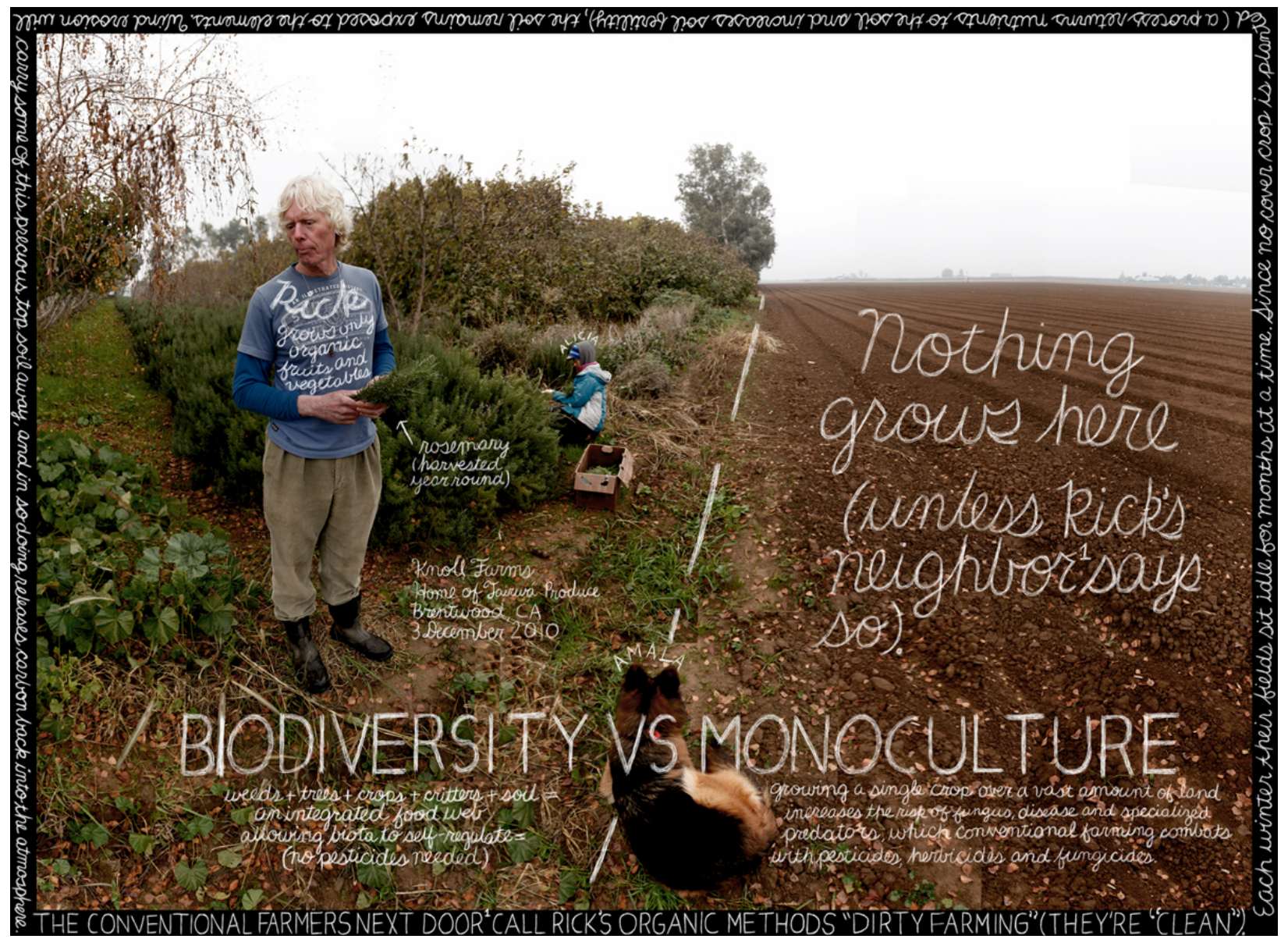

Figure 2. In Biodiversity vs. monoculture, Gayeton captures in one image a rare instance of one term immediately adjacent to its opposite (p. 115). Image used with permission of The Lexicon of Sustainability. 
footnotes in white cursive that adorned new food economy, relocalize, and slow fast food (p. 40-45) three entries inspired by a partnering farm, slaughterhouse, and restaurant in the Athens, Georgia, area. Most art, after all, looks best hung a large format, liberating viewers from the task of turning pages with bifocals. Harper Design, the publisher, probably had this in mind when it equipped the book with icons that readers with iOS or Android mobile devices can scan to instantly view the associated short film on their phone or tablet. I found this to be a convenient way to dive deeper, even as I wished for an alphabetical index so that I could reference my "favorite" artworks more quickly.

People already versed in sustainable agriculture systems could still learn a lot from this book, as it covers a surprisingly wide spectrum of issues. I better understand the buzz about biochar (p. 121123), for example, and added some new terms like "cow to pick up truck" index (p. 182) to my vocabulary. I also feel I've met a wider spectrum of innovators around the country whose work is quilting together, stitch by stitch, a series of more creative, diverse, and resilient food networks.

The question, then, is not whether Gayeton's glossary is accurate or comprehensive. It's whether his theory of change (simply put, that "Your words can change the world," which he says at the close of every short film) holds water, especially when it comes to the seemingly Sisyphean task of tackling (or even slightly mitigating) climate change.

According to the CGIAR Research Program on Climate Change, Agriculture, \& Food Security (CGIAR CCAFS), food production and consumption along the supply chain (including fertilizer manufacture, agriculture, processing, transport, retail, household food management, and waste disposal) contribute 19 to 29 percent of total greenhouse gas emissions each year. Food is no small potatoes when it comes to carbon footprint, then, responsible for more than half of all non-carbon dioxide greenhouse gas emissions (CGIAR CCFAS, 2014).

The hypothesis behind the Lexicon of Sustainability is compelling. Now more than ever, food decisions for conscientious consumers are crippling. If their confusion means they can't muster a humble elevator pitch in casual conversa- tion about the risks posed by GMOs, why they pay more for fish with a traceable value chain, or why they want to start keeping bees, then the notion of voting with one's fork has limited power. We tune out vocabulary we don't understand, avoid dialogue or questions that make us feel ill-informed or hopeless, and thereby enable a cycle of peripheral awareness that looks dangerously like apathy. And the corporate food monopolies take advantage of this whenever they can — on packaging, in advertising, and in lobbying efforts designed to "protect us" from too much information. Some observe that label fatigue afflicts us in the food aisles. Corporate sustainability efforts on the part of food retailers to calculate and reduce carbon footprints by using compact fluorescent light bulbs or reducing packaging by 10 percent, for example, are what a cynic might call "polishing a turd," in the interest of marketing to the more conscientious consumer. Such self-reported scores, footprints, and rankings all serve to retain control over people's understanding of the issues, further distancing them from practical solutions.

Information asymmetry undermines the ability, so often touted by free market economists, for consumers to shift demand toward products with preferred characteristics. In her 2009 book, Cheap, Ellen Ruppel Shell offers an interpretation Gresham's Law, in which a quart of high quality milk and a quart of watered-down milk cannot sell for the price of their respective real values if the customer is unable to distinguish quality. Instead, an average price would predominate, with lower quality milk selling for more than it's worth, and the higher quality milk selling for less than it's worth. Eventually, the producers of the better milk go under, and the "watered-down milk sellers flourish" (Shell, 2009, p. 6).

When I interviewed Gayeton about his book, he offered an even better analogy: "If someone walked up to you on the street and said 'Close your eyes, let me put something in your mouth,' would you let them?"

The word "gross" came to my lips more readily than yes or no. "But essentially, that's what we do every day," Gayeton noted (personal communication, July 15, 2014).

He continued, "consumers now have more 
responsibility than they ever have. FDA and USDA [U.S. Department of Agriculture] will not fix a failed food system" (personal communication, July 15, 2014). Nevertheless, Gayeton does not seem hopeless about the power of policy. In fact, part of the Lexicon of Sustainability includes Project Localize, a curriculum being piloted at 25 high schools in the U.S., and even two schools in Oaxaca and Guadalajara, Mexico, where the curriculum was translated into Spanish. In 2013, students from Ames, Iowa, took their artwork to members of Congress and the USDA to urge policymakers to control "the level of transparency about what goes into food" (personal communication, July 15, 2014), whether it's over fertilization, use of pesticides linked to bee depopulation, or use of ingredients with adverse environmental or human health impacts.

The idea that language is fundamental to social movements is nothing new. The power to bestow names on objects, people, places, and philosophies is undervalued, so we hardly notice when it gets abused. Noam Chomsky famously observed that destructive paradigms thrive because they impose on people "the feeling that they really are incompetent to deal with complex and important issues: they'd better leave it to the captain" (Chomsky, 1987 , p. 42). The scientific and seemingly apocalyptic lingo of climate change, for example, leaves us fatigued. Acclaimed documentary films and books revealing the truths and consequences behind our comfortable lives relegate actionable solutions to the rushed final moments before the credits roll. Like tabloid headlines, every "Top Five Things You Can Do to Reduce Your Diet's Carbon Footprint!" seems like a set of tepid compromises between the contradictory messages coming from environmentalists on the one hand and nutritional faddists on the other: Don't eat meat... but eat grass-fed meat! Eat local...but replace gluten with coconut flour and a rotating carousel of tropical superfoods, at least until stories emerge that the harvest of said superfood is endangering native culture and ecology! Even the most uncontentious, no-brainer lifestyle changes can seem like moot points in the global context.

Gayeton calls his book a response to what he refers to as "Crisis Cults" that only focus on prob- lems. With no shortage of potential catastrophes (rising seas, obesity, diabetes, increasing incidences of cancer, corporate monopolies, loss of top soil, contaminated groundwater), muckrakers emerge from every field like popping prairie dogs to elevate otherwise buried issues. But for Gayeton, crisis cults are "a bigger enemy" than the industrial food system they are fighting, since their focus on what is wrong tends to paralyze people with guilt rather than empower with inspiration.

The belief that sustainability literacy is the first step in a new direction underlies Gayeton's strategy to "create a thought bomb, an idea that people can't easily forget. Once they learn it, they can't unlearn it" (personal communication, July 15, 2014). I would argue that words alone are not enough, but if armed with examples of other innovators, leaders, and average people "doing the right thing," people will inevitably change the way they eat. After all, isn't new vocabulary easier to remember when you read a sample sentence using it? Context is everything.

The stories of "solutionaries" may not be as sensational as those offered by muckrakers, but I would agree that they are more likely to engender action. People naturally gravitate toward solutions, and Local's strength is not only the variety and sheer number of solutions, but also that each is accompanied by a person and a place. In practical terms, this lexicon enables the possibility of a common language that enables conversation. Talking about "How to fix climate change" could be a long, ugly slog of a conversation, while talking about an urban gardener who milks a goat in her kitchen is easy, and maybe a little fun. While an albeit beautiful poster or three-minute film cannot fully convey the backstory, each offers an unintimidating invitation to learn more; the website offers a natural path for that.

In a way, the book is in keeping with researchers who have suggested that broad descriptors like "local" offer an incomplete and unsatisfactory entry into food systems, depriving consumers of a realistic understanding of examples. "Activists and organizers will need to innovate beyond standard marketing techniques, with the aim of communicating honestly and clearly about the complexity surrounding food production and consumption, 
while also motivating commitment based on realistic understanding of the issues" (Hinrichs \& Allen, 2008 , p. 348). Others suggest that confusion around what "local" means could stunt its development, and recommend instead a taxonomy of geographical, relational, and values proximities (Eriksen, 2013).

Whether an expanded, more detailed food vocabulary can really empower normal folk to shift their perceptions and purchasing patterns is really a question left up to us. Words thrive on usage, and Local's lexicon is more than an academic glossary. Whether it's through a pop-up art show in your community, nominating a school or teacher for Project Localize, gifting the book to your Aunt Helen, or sharing the short films on social media, we now have a new tool to initiate conversation. Why wait?

\section{References}

Chomsky, N. (1987). The Chomsky reader. New York: Pantheon.

Consultative Group on International Agricultural Research, Research Program on Climate Change, Agriculture and Food Security [CGIAR CCAFS]. (2014). Big facts: Direct agricultural emissions. Retrieved from http://ccafs.cgiar.org/bigfacts 2014/\#theme $=$ food-emissions\&subtheme $=$ directagriculture

Eriksen, S. N. (2013). Defining local food: Constructing a new taxonomy - Three domains of proximity. Acta Agriculturae Scandinavica, Section B - Soil \& Plant Science, 63(Supp. 1), 47-55. http://dx.doi.org/10.1080/09064710.2013.798682

Hinrichs, C. C., \& Allen, P. (2008). Selective patronage and social justice: Local food consumer campaigns in historical context. Journal of Agricultural and Environmental Ethics, 21(4), 329-352. http://dx.doi.org/10.1007/s10806-008-9089-6

"LOCAL": The book. (n.d.). The lexicon of sustainability. Retrieved Aug. 16, 2014, from http://www.lexiconofsustainability.com/local-thebook/\#

Schell, E. R. (2009). Cheap: The high cost of discount culture. New York: Penguin. 